Neurosurg Focus 24 (5):E7, 2008

\title{
Radiation-induced meningioma
}

\author{
Felix Umansky, M.D., Yigal Shoshan, M.D., Guy Rosenthal, M.D., \\ Shifra Fraifeld, M.B.A., And Sergey Spektor, M.D., Ph.D. \\ Department of Neurosurgery, Hadassah-Hebrew University Medical Center, Jerusalem, Israel
}

\begin{abstract}
$\checkmark$ The long-term or delayed side effects of irradiation on neural tissue are now known to include the induction of new central nervous system neoplasms. However, during the first half of the 20th century, human neural tissue was generally considered relatively resistant to the carcinogenic and other ill effects of ionizing radiation. As a result, exposure to relatively high doses of $\mathrm{x}$-rays from diagnostic examinations and therapeutic treatment was common.

In the present article the authors review the literature relating to radiation-induced meningiomas (RIMs). Emphasis is placed on meningiomas resulting from childhood treatment for primary brain tumor or tinea capitis, exposure to dental x-rays, and exposure to atomic explosions in Hiroshima and Nagasaki. The incidence and natural history of RIMs following exposure to high- and low-dose radiation is presented, including latency, multiplicity, histopathological features, and recurrence rates. The authors review the typical presentation of patients with RIMs and discuss unique aspects of the surgical management of these tumors compared with sporadic meningioma, based on their clinical experience in treating these lesions. (DOI: $10.3171 /$ FOC/2008/24/5/E7)
\end{abstract}

KEY WORDS • ionizing radiation • radiation-induced meningioma • tinea capitis

$\mathrm{T}$ HE DISCOVERY OF roentgen rays, or X-rays, is credited to Wilhelm Conrad Roentgen, who noticed in November 1895 that a fluorescent screen on a nearby table began to glow when free electrons were generated in a vacuum tube. Roentgen's discovery created a furor. During 1896 alone, the use of x-rays was described in nearly 1000 articles in leading scientific journals, textbooks on $\mathrm{X}$-rays and radioactivity, and newspapers worldwide..$^{38}$

Within months, Henry Becquerel attributed fogging on unexposed photographic plates in his lab to an invisible emission from uranium. Marie and Pierre Curie discovered other radioactive elements and developed techniques to purify radium from pitchblende. Many other brilliant scientific discoveries followed-more than 20 Nobel prizes were awarded for research relating to $\mathrm{x}$-rays and radiation during the 20th century. With the discovery of the phenomenon of nuclear fission in Germany in 1938, and the first demonstration at the University of Chicago during the 1940s, the nuclear age began.

Roentgen's discovery quickly led to the invention of $\mathrm{x}$ ray machines to image structures in the body and treat health conditions. Broad diagnostic and therapeutic benefits were apparent immediately. For many years, radiation was used freely for medical applications in very large doses, with no protection for patients, physicians, or auxil-

Abbreviations used in this paper: $\mathrm{CT}=$ computed tomography; $\mathrm{MR}=$ magnetic resonance; $\mathrm{RIM}=$ radiation-induced meningioma; $\mathrm{SM}=$ spontaneous meningioma; $\mathrm{WHO}=$ World Health Organization. iary personnel (Fig. 1). For example, at least as late as 1930, women were exposed to radiation during pregnancy for the treatment of pelvic disease. A high incidence of anomalies was later reported among children who were thus irradiated in utero. ${ }^{19}$

Radium also became a marketer's dream, and products such as bottled radium water, toothpaste, suppositories, and glowing radium cocktails were popular. ${ }^{11}$

There was early evidence that x-rays could harm tissue. Many radiography workers developed skin lesions and even lost their fingers. Thomas Edison, a prolific American inventor and businessman, is credited with designing and producing the first commercially available fluoroscope. His basic design is still in use, but he abandoned his work with x-rays in 1903 after his own eyesight was damaged and his assistant, Clarence Dally, lost an arm, fingers, and eventually his life due to extensive experiments with x-rays (Fig. 2). Edison said at the time, "Don't talk to me about X-rays, I am afraid of them." 15

Precautionary measures were suggested in Germany as early as $1913 .{ }^{23}$ In several British studies examining the effects of total-body irradiation on radiologists, investigators reported relatively shorter life spans in those entering the specialty before exposure standards were established in the United Kingdom in $1921 .{ }^{34}$ Formal guidelines were established in the US during the 1930s..$^{23}$ Over the years, there has been a trend toward more rigorous protection standards after the recognition of the long-term health effects due to exposure to radiation. ${ }^{25}$

Additional evidence of risk from x-ray exposure emerged in 1927, when Hermann Joseph Muller (1890- 

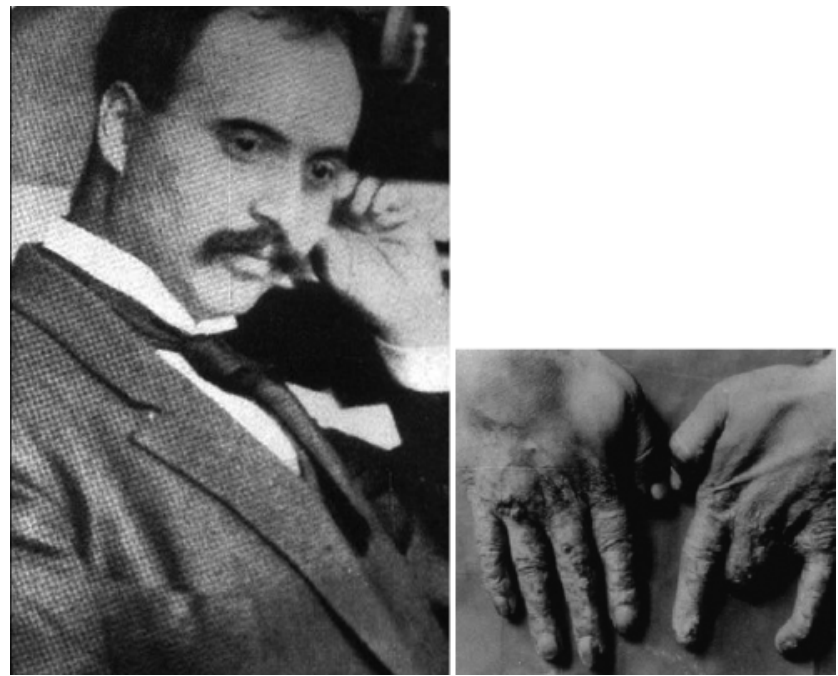

FIG. 1. Left: Photograph of Mihran Kassabian, director of the Roentgen Ray Laboratory at the Philadelphia Hospital. He performed x-ray examinations in more than 3000 patients. Right: He photographed and documented damage to his hands, including progressive necrosis and serial amputations. He died of radiationinduced cancer in 1911. Used with permission of the copyright holder, Radiology Centennial, Inc.

1967), a founder of 20th century genetics, published evidence in Science that x-ray exposure produced a 150 -fold increase in the natural mutation rate of fruit flies and that the rate of mutations was proportional to the dose. ${ }^{40} \mathrm{He}$ showed that $\mathrm{x}$-rays broke apart and rearranged the genes. In 1946, this research was recognized with the Nobel Prize in Medicine. Muller spoke against needless exposure to xrays in medicine and urged protection for individuals routinely exposed to ionizing radiation.

Neurological tissue was long considered relatively resistant to damage from $\mathrm{x}$-rays, ${ }^{16,24,45}$ and some authors suggested that higher doses allowed longer survival in patients with glioblastoma multiforme..$^{6,61}$ In 1938, Davidoff et al. ${ }^{13}$ described the clinical and histological effects of delivering
10-50 Gy in a single exposure, or 48-72 Gy in 2 fractions, applied directly to the brains and spinal cords in monkeys. The authors observed profound physiological and morphological changes, which were especially marked in the glia and nerve tissues. The intensity of histological change was determined primarily by x-ray dose and, to a lesser extent, by the time lapsed between irradiation and autopsy. Clinical and histological changes were progressive. Other authors also documented pronounced degenerative effects on nerve tissue from exposure to ionizing radiation. ${ }^{31,46,79}$

However, only after atomic bombs were dropped on Nagasaki and Hiroshima, and atomic tests were performed during the 1950s, did the general public and much of the medical community became aware of risks from exposure to ionizing radiation. ${ }^{4,34,43}$ In 1956, the Committee on Biological Effects of Atomic Radiation of the National Academy of Sciences introduced the concept of regulating the overall dose to the general population, suggesting a 0.1-Gy limit during the reproductive years, a span averaging 30 years. ${ }^{44}$

Today we know that exposure to ionizing radiation overcomes the binding energy of electrons orbiting atoms and molecules. In biological material, hydroxyl radicals formed by $\mathrm{x}$-ray interaction with water molecules cause strand breaks or base damage in nearby DNA. The x-rays may also ionize DNA directly. While most radiation-induced damage to DNA is repaired by mechanisms within the cell, double-strand breaks are more difficult to repair, and occasional misrepair can result in point mutations, chromosomal translocations, and gene fusions, all of which have the potential for induction of cancer. ${ }^{10}$

Radiation-induced changes to neural tissue are now known to include visual deterioration, hearing loss, hormonal disturbances, vasculopathy, brain and bone necrosis, atrophy, demyelination, calcification, fatty replacement of bone marrow, and induction of central nervous system neoplasms ${ }^{3,55}$ and are increasingly evident radiologically. ${ }^{55} \mathrm{~A}$ dose effect has been documented for many changes, including tumor induction. ${ }^{34,53,62,63,71,72}$

Both $\mathrm{x}$-rays and gamma rays are forms of ionizing radiation, which is defined as radiation that has sufficient ener-
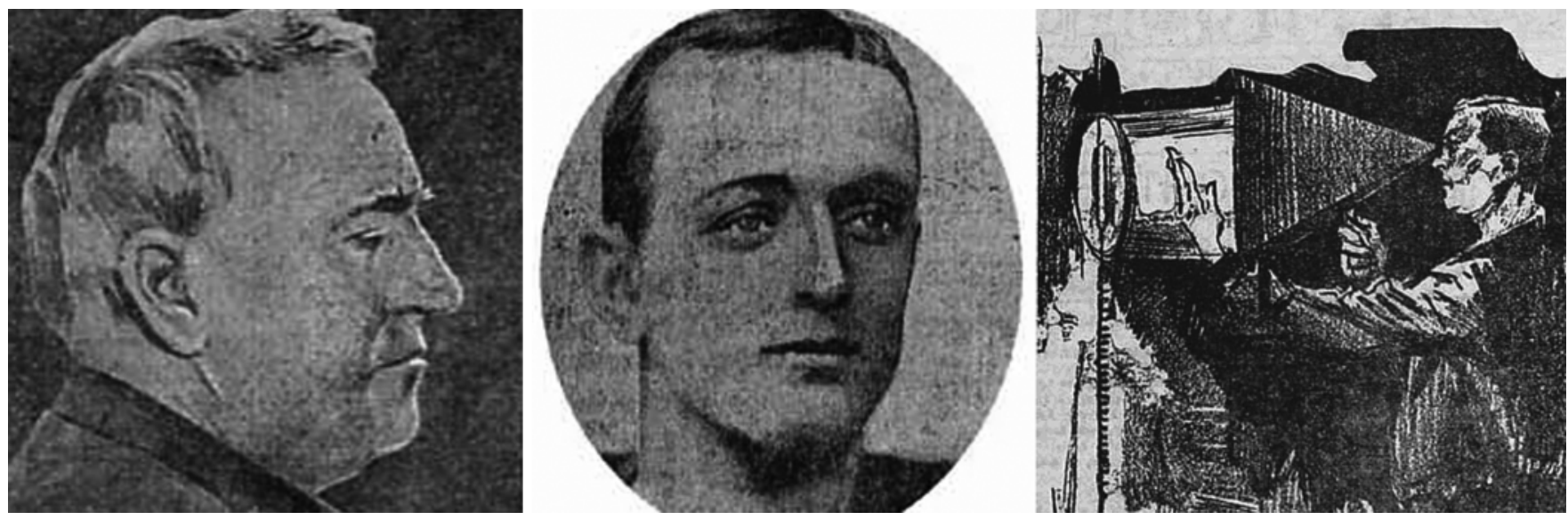

FIG. 2. Thomas Edison (left), credited with invention of the fluoroscope, abandoned his work with x-rays after his own eyesight was damaged. His assistant, Clarence Dally (center), lost fingers, then an arm, and eventually his life to metastatic skin cancer. Fluoroscopists tested the calibration of their instruments by placing their hands in the rays' path (right). Used with permission of the copyright holder, Radiology Centennial, Inc. 
gy to displace electrons from molecules. Free electrons can damage human cells. At very high doses, the damage inflicted on tissues is evident within days of exposure. Lateonset effects such as cancer and other neoplasms, however, may develop even with exposure to relatively low doses.

\section{Radiation-Induced Meningioma}

Radiation-induced meningioma is the most common brain neoplasm known to be caused by ionizing radiation. ${ }^{3,28}$ Harrison et al. ${ }^{24}$ grouped RIMs into 3 categories: those due to high-dose ( $>20 \mathrm{~Gy}$ ), intermediate-dose $(10-20 \mathrm{~Gy})$, and low-dose $(<10 \mathrm{~Gy})$ radiation. Other authors define doses $>10 \mathrm{~Gy}$ as high. ${ }^{42,78}$

\section{High-Dose RIMs}

In 1953, Mann et al. ${ }^{33}$ described a meningioma in a 4year-old girl who had undergone radiation treatment for optic nerve glioma. The child's meningioma eventually became malignant. Several authors have summarized up to 126 cases of high-dose RIMs reported in the literature between 1953 and 2002., 17,42,66,67,78,81 The radiation doses ranged from 22 to $87 \mathrm{~Gy}$, and the majority of patients had undergone radiotherapy as children. The mean latency from irradiation to diagnosis of the meningioma was $\sim 19$ years, ${ }^{42,67}$ with a tendency for shorter latency in patients treated with higher doses and those who had undergone radiotherapy at younger ages. $2,17,24,32,42,78$

\section{Low-Dose RIMs}

The increased incidence of meningiomas following exposure to low-dose radiation has been reported in patients who, as children, had undergone radiation treatment for tinea capitis, those whose heads and necks were exposed to medical and dental x-rays at a young age, and survivors of the atomic explosions in Hiroshima and Nagasaki.

Irradiation for Tinea Capitis. Prior to the introduction of griseofulvin in 1960, ${ }^{18,27,60,82}$ the world standard for treatment of tinea capitis was scalp irradiation., ${ }^{5,72,59}$ Treatment for tinea capitis was administered using the AdamsonKeinbock technique, which was designed to irradiate the entire scalp as uniformly as possible through exposure to 5 overlapping treatment areas. ${ }^{1}$ Phantom studies using this technique showed that the radiation dose to the scalp was 5-8 Gy, the surface dose to the scalp was 5-8 Gy, the surface dose to the brain was 1.4-1.5 Gy, and the skull base received an average of 0.7 Gy. ${ }^{5}$ In 1966, Albert et al. ${ }^{5}$ reported a substantial increase in cancer, mental disease, and permanent damage to scalp hair in 1908 patients in whom radiotherapy was performed for tinea capitis at the New York University Medical Center between 1940 and 1958, compared with 1801 patients treated for tinea capitis without radiotherapy during the same years. Other reports followed. 7,20,24,41,59,76

In 1974, Modan and colleagues ${ }^{37}$ at the Sheba Medical Center in Tel Aviv published a retrospective cohort study showing a significantly higher risk of malignant and benign head and neck tumors among $\sim 11,000$ Israeli adults treated for tinea capitis as children. This major epidemiological work is widely credited as proving the causal role of radiation in the development of meningiomas in some patients.
Follow-up studies of the Israeli cohort showed that a radiation dose of only 1-2 Gy administered during childhood led to a 9.5-fold increase in meningioma incidence. ${ }^{57}$ Continuing follow-up ${ }^{63-65}$ shows that elevated risk of brain tumor, including meningioma, is positively associated with dose, with excess relative risk for benign meningioma rising to 18.82 for doses $>2.6$ Gy. ${ }^{63}$ These studies showed a higher prevalence of calvarial tumors and multiple meningiomas, and higher recurrence rates in RIMs than SMs. The mean latency was $\sim 36$ years.

Low-Dose RIM Due to Dental Radiographic Examination. In 1953, Nolan alone ${ }^{50}$ and with Patterson ${ }^{51}$ published studies in which significant blood changes occurred in patients exposed to 1.15-2.8 Gy during full-mouth radiographic examinations. Nolan observed that full-mouth series delivered converging lines of radiation, with high points near the meninges. In 1980, nearly 30 years later, Preston-Martin et al. ${ }^{54}$ noted a higher incidence of meningioma in women with a history of full-mouth dental x-rays. The risk in this cohort study was higher in patients who had undergone radiographic examinations as children or teenagers and in those in whom radiographic examinations were conducted before 1945, when doses were higher. The majority of tumors were located in the tentorial or subtentorial region. The authors of more recent case-control studies in Sweden ${ }^{56}$ and the US ${ }^{29}$ have found that dental radiographic examinations performed during the adult years may also increase the risk of meningioma.

Radiation-Induced Meningiomas in Survivors of Atomic Bombs Dropped on Hiroshima and Nagasaki. The increased incidence of meningiomas among survivors of the 1945 atomic explosions in Japan was shown only in 1994, when Shibata et al. ${ }^{70}$ demonstrated a higher incidence of meningiomas in survivors of the bombing in Nagasaki. In 1997 Shintani et al..$^{71,72}$ published similar findings after studying data obtained in Hiroshima survivors. Due to the relatively low-dose exposure to ionizing radiation among these survivors compared with those undergoing radiotherapy for tinea capitis, the average latency was greater in the Japanese studies. The risk of meningioma induction was shown to increase with closer proximity to the bombs' epicenters and in those exposed during childhood..$^{53}$

\section{Clinical Presentation}

Radiation-induced meningiomas typically display female preponderance, although the difference between sexes may be less distinct compared with SMs. $32,42,53,56,64,67,80$ Strojan et al. ${ }^{78}$ reported female predominance of 1.33:1 in a survey of 126 cases of high-dose RIMs. In a review of the incidence of central nervous system tumors among survivors of the atomic bombs in Hiroshima and Nagasaki, Preston et al..$^{53}$ found that excess relative risk for RIMs is higher in men than in women.

Scanty hair, or alopecia, and an atrophic scalp are hallmarks of irradiation. ${ }^{24,55,59,73}$ We are also of the impression that microcephaly is increased in patients with low-dose RIMs compared with the general population, although no evidence has been reported in the literature. Microcephaly most likely results from premature closure of the skull sutures when radiation is administered to the head in young children. 


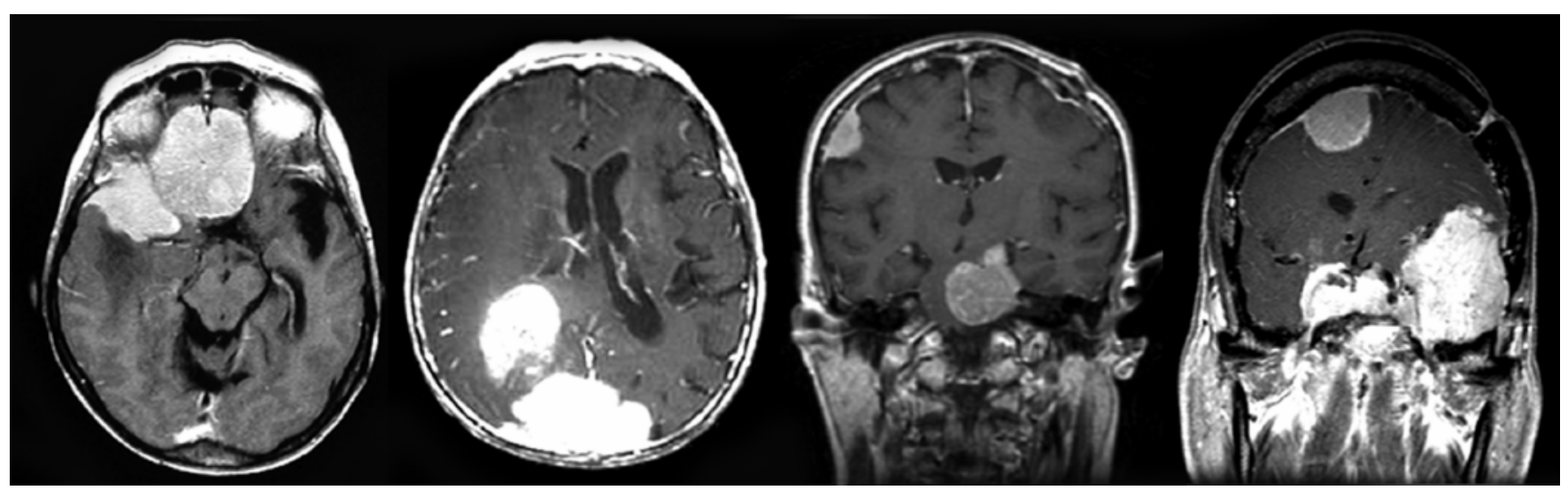

FIG. 3. Multiplicity is elevated in RIM.

The location of the RIM is primarily related to the site of exposure. The authors of several large studies conducted in Israel have documented a primarily calvarial location in patients treated for tinea capitis..$^{59,64,75}$ Ghim et al. ${ }^{17}$ found that 11 of 13 pediatric patients with high-dose RIMs had calvarial meningiomas, whereas skull base meningiomas were found in 4-19\% of patients with RIM in whom there was a history of high-dose irradiation for primary brain tumors. ${ }^{39,59,67,76}$ Epidemiological studies of patients with RIM linked to full-mouth dental x-rays have shown that skull base meningiomas are more common following this type of radiation exposure..$^{54}$

The latency period between exposure and clinical diagnosis of meningioma varies with radiation dose and age at initial treatment. Sadetzki et al. ${ }^{64}$ reported a 36.3-year average latency (range 12-49 years) in the Israeli low-dose cohort study. In a thorough review of the literature, Harrison et al. ${ }^{24}$ calculated that a mean of 35.2 years elapsed between low-dose irradiation $(<10 \mathrm{~Gy})$ and diagnosis, whereas a mean of 26.1 and 19.5 years, respectively, elapsed in patients receiving moderate (10-20 Gy) and high-dose $(>20 \mathrm{~Gy})$ treatment. In their survey of reported cases of RIM in patients exposed to high-dose radiation, Strojan et al. ${ }^{78}$ observed average latency of 18.7 years and also noted shorter latency in patients in whom radiation treatments were administered at younger ages. Ghim et al. ${ }^{17}$ found a mean latency of only 10.8 years (range 5-15.5) in a study of 13 pediatric high-dose RIM patients with mean age at diagnosis 13 years (range 6-18). These patients had been treated for brain tumors at an average age of 2.5 years. A 14-month latency period was reported in an 11-year-old boy following high-dose irradiation for a tumor in the posterior fossa. ${ }^{12}$

Radiation-induced meningioma differs from SM in patient age at presentation and in the multiplicity, aggressiveness, and rate of tumor recurrence. Mean age at presentation is reported as 29.2-37.9 years in patients exposed to high-dose radiation ${ }^{2,14,24,41,66,67,75}$ and $45-58$ years in those who received low-dose treatment, ${ }^{2,24,52,59,76}$ whereas SM generally arises in the 5th or 6th decade of life.

The incidence of multiple lesions is elevated in both patients with low- and high-dose RIMs, and it ranges from 4.6 to $18.7 \%$ of cases. ${ }^{59,76}$ Multiplicity has been reported in $15.8 \%$ of patients with RIMs, compared with $2.4 \%$ of those with SMs in the Israeli cohort study. ${ }^{64}$
Protocols for MR and CT imaging of RIM and SM are comparable. The appearance of RIM on MR and CT images is comparable with SM; thus, the differential diagnosis cannot be based on imaging studies. The presence of multiple meningiomas in a patient with a history of head irradiation, as well as typical skin changes, raises the suspicion of RIM (Fig. 3).

Meningotheliomatous, transitional, and fibroblastic histological subtypes are the most common in RIM.,76 Histological features are distinctive compared with SM. Soffer et al. ${ }^{76}$ have noted high cellularity, nuclear pleomorphism, an increased mitotic rate, focal necrosis, bone invasion, and tumor infiltration of the brain in a series of 42 patients with low-dose RIM. Rubinstein et al. ${ }^{59}$ reported several findings: a high degree of cellularity; pleomorphic nuclei with great variation in nuclear size, shape, and chromatin density; numerous multinucleated and giant cells; and nuclei with vacuolated inclusions. They also noted frequent mitoses, psammoma bodies, foam cells, and thickened blood vessels

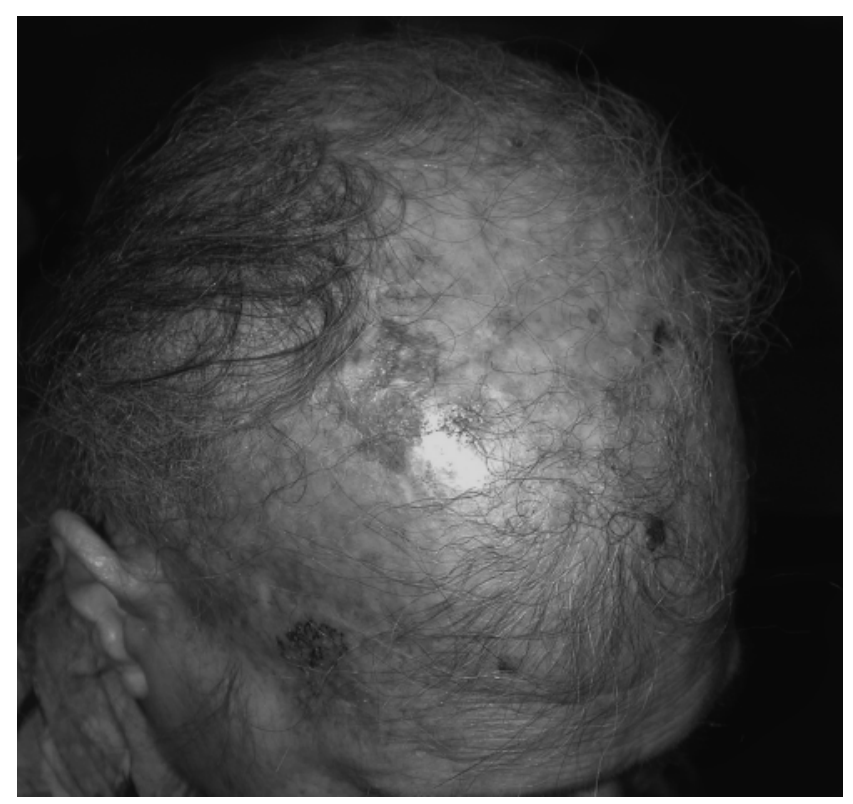

FIG. 4. Photograph of a patient with an RIM and related alopecia and scalp atrophy. 


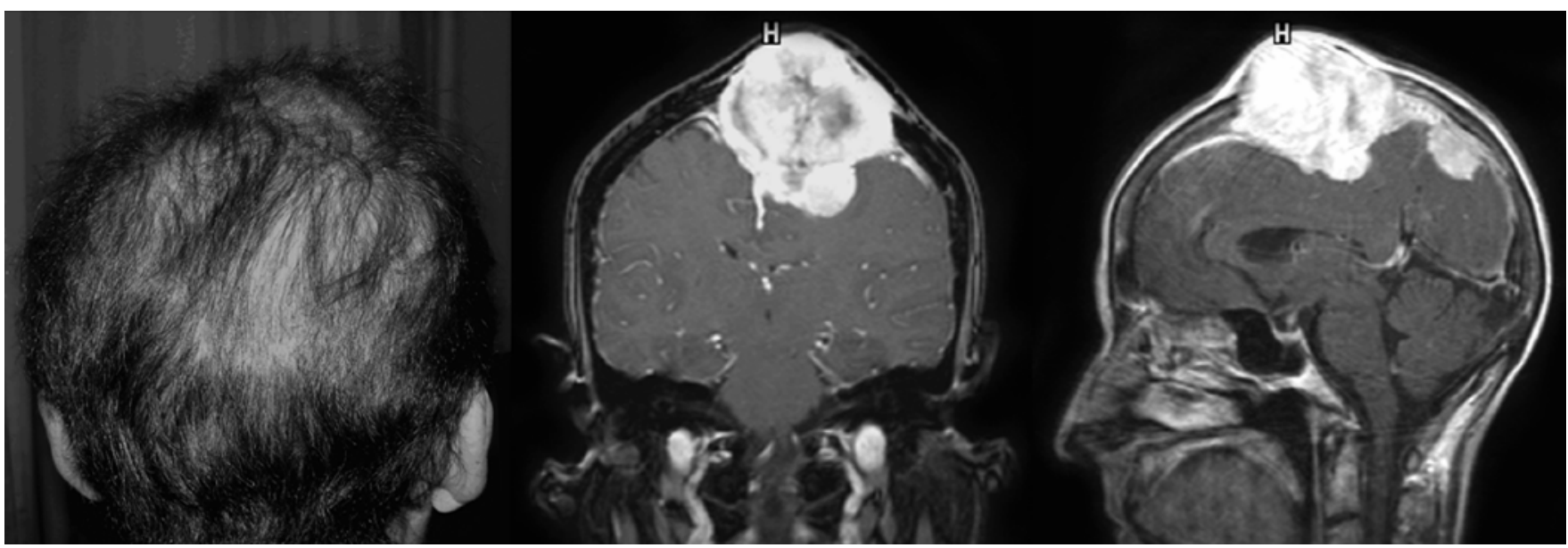

FIG. 5. Studies obtained in a 56-year-old woman who had undergone radiotherapy for tinea capitis at age 6 years. A: In recent years she had detected a growing lump on her scalp and had recently developed difficulty walking. B and C: Axial and sagittal CT scans revealed a large parasagittal meningioma. Magnetic resonance imaging had also shown an additional small, parasellar meningioma (data not shown). Note the presence of alopecia, a hallmark of radiation to the scalp.

that did not stain for amyloid. Louis et al. ${ }^{30}$ found that RIMs were more often atypical, or aggressive and multifocal, with higher proliferation indices than SMs. Musa et al. ${ }^{42}$ reported a $23 \%$ incidence of atypia or malignancy among 79 cases of high-dose RIM.

Radiation-induced meningiomas may also exhibit more aggressive clinical behavior than SMs, 20,24,52,59,67,76 including high recurrence rates following surgery and radiotherapy. Rubinstein et al. ${ }^{59}$ noted a $25.6 \%$ recurrence rate in 43 patients with RIM, and $11.6 \%$ of this group experienced multiple recurrences, compared with an $11.4 \%$ recurrence rate in 258 patients with SMs in their series. Both groups were followed for only 4 years. Higher recurrence rates in patients with RIMs than those with SMs have also been reported elsewhere. .4,76 $^{64}$

In a preliminary investigation, we found evidence of increased recurrence rates similar to those seen in other studies, but there was a significantly higher rate of multiplicity and much higher frequency of atypical (WHO Grade II) and anaplastic (WHO Grade III) histopathology in patients with RIMs compared with SMs treated in our institution (F. Umansky et al., unpublished data).

\section{Management of RIM}

\section{Surgical Intervention}

Surgical removal is the treatment of choice for most cases of RIM, although complete and safe resection may not be possible due to the lesion's frequent multiplicity, involvement of osseous structures and vessels, and aggressive nature. Paradoxically, stereotactic radiosurgery or fractionated stereotactic radiosurgery may be appropriate adjuncts to surgery or may be performed in lieu of surgery in some patients, despite the radiation-related origins of RIMs. In some patients, angiography may be appropriate for visualization of the tumor's vascular anatomy and preoperative embolization.

The first consideration when planning the surgical approach for resection of RIM is often scalp atrophy, followed by multiplicity and the high rate of recurrence. The scalp may be slightly or severely atrophic and poorly vascularized, depending on the radiation dose received. In some patients, the thickness of the entire galeal/skin flap may reach only $1.5-2 \mathrm{~mm}$, necessitating careful planning and meticulous technique to avoid cerebrospinal fluid leakage and skin flap dehiscence. The risk of these complications increases in patients with an atrophic scalp who require multiple craniotomies, which is a common scenario in the RIM population (Fig. 4). In such cases, it may be appropriate to include a plastic surgeon on the team.

A large percentage of RIMs are located at the calvaria, and in cases of parasagittal or falcine meningiomas preoperative assessment of the superior sagittal sinus is critical in planning surgery (Fig. 5). We prefer the use of MR imaging with MR venography for assessment of patency, although angiography may be required in rare cases. In patients with highly vascular tumors, preoperative embolization may be beneficial.

If healthy skin is available at the periphery of the irradiated, atrophic scalp, it should be used..$^{42}$ In our experience, skin damage is often less severe in the low forehead, low temporal, or occipital areas compared with the convexity and vertex. When skin in these basal areas is indeed healthier and better vascularized, incisions may be made more inferiorly than usual. Use of hemostatic clamps or coagulation is not advised as they may further damage this fragile skin and may cause drying or shrinkage of the skin edges. Straight or slightly curved incisions are preferred to horseshoe contours, and flap size should be held to the minimum.

Given the aggressive nature and high recurrence rates of RIMs, wide resection margins in the involved dura mater are vital. $8,9,26,74,80$ In cases in which the tumor involves under- or overlying bone, the osseous portion of the tumor should be radically removed,,$^{24,59,7,77,80}$ because osseous invasion has been linked to higher rates of tumor recurrence. ${ }^{26,74}$ When we find bone flap invasion or suspect it has 
occurred, we autoclave the flap or replace it with acrylic graft. Recurrence rates are higher among patients with tumors involving the skull base or a major cranial sinus, where wide resection margins are often impossible to achieve. . $36,74^{-74}$

Fragile skin conditions frequently necessitate special considerations when closing the wound. Multilayer closure may be impossible, especially in convexity meningiomas, since the atrophic scalp may not accept additional sutures. In patients with a very thin scalp, we close the skin and galea aponeurosis with a single layer of running 3-0 sutures, with or without locking, using nylon, not Vicryl. This closure should be performed carefully to provide a single, watertight layer, capable of preventing cerebrospinal fluid leakage; however, if the stitches are closed too tightly, skin necrosis may result and cause potentially serious consequences. Staples are not suitable for closure in these patients. They provide poor approximation, without hermetic closure, and can easily damage a fragile, atrophic scalp.

\section{Stereotactic Radiosurgery and Fractionated Stereotactic Radiotherapy}

Surgery may be followed by radiotherapy in patients with RIMs if radical excision cannot be achieved. When patients have already received the maximum tolerable dose of radiation, stereotactic radiotherapy or stereotactic radiosurgery may be preferable to conventional radiotherapy. Adjuvant conventional conformal radiation is generally recommended following surgery or radiosurgery to treat viable tumor cells that remain along the dura and in brain parenchyma in patients with atypical (WHO Grade II), anaplastic (WHO Grade III), or malignant (WHO Grade IV) meningiomas. ${ }^{8,980}$ Careful consideration should be given to original doses and treatment fields when planning new therapeutic irradiation.

\section{Other Therapies}

Systemic treatment with tamoxifen ${ }^{21}$ and hydroxyurea $^{35,47-49,58,68,69}$ has been attempted as an adjuvant therapy in patients with recurrent, unresectable SMs. In the past, we have used both of these agents in selected RIM patients with recurrent tumors when surgery and radiotherapy failed, with no measureable response. In our experience, these agents did not provide measurable clinical benefit for the management of meningioma.

\section{Conclusions}

Exposure to ionizing radiation has been shown to significantly increase the risk of meningioma, a solid tumor arising from cells of the meningeal coverings of the brain. The risk of meningioma formation increases, and the latency period between exposure and tumor development decreases, with higher doses of radiation; however, exposure to even low radiation doses has been shown to significantly increase the risk of meningioma. . $3,62,69-72^{-1}$

The Israeli experience has shown that even low-dose radiation in children leads to a high and significant increase in the risk of developing meningioma. This risk should be considered when decisions are made to use radiation in routine imaging examinations, such as CT scanning, ${ }^{10}$ or to administer higher doses of radiation for treatment of benign tumors during childhood, adolescence, and young adulthood. ${ }^{2-4,17,42,78,81}$

Radiation-induced meningiomas are characterized by marked changes to the scalp, including alopecia, atrophy, and poor vascularization. Patients with RIMs frequently present with multiple tumors. Compared with SMs, a higher proportion of RIMs are atypical or anaplastic, and recurrence rates are higher. Poor skin condition may necessitate adjustment of the surgical approach and skin flap placement. Paradoxically, stereotactic radiotherapy may be used to treat patients with unresectable or residual/recurrent tumors.

\section{Disclaimer}

The authors did not receive outside support for research or preparation of this article. Furthermore, the authors have no conflicts of interest relating to companies mentioned or relevant to its subject.

\section{References}

1. Adamson H: A simplified method of X-ray application for the cure of ringworm of the scalp: Keinbock's method. Lancet 1: 1378-1380, 1909

2. Al-Mefty O, Kadri PA, Pravdenkova S, Sawyer JR, Stangeby C, Husain M: Malignant progression in meningioma: documentation of a series and analysis of cytogenetic findings. J Neurosurg 101:210-218, 2004

3. Al-Mefty O, Kersh JE, Routh A, Smith RR: The long-term side effects of radiation therapy for benign brain tumors in adults. $\mathbf{J}$ Neurosurg 73:502-512, 1990

4. Al-Mefty O, Topsakal C, Pravdenkova S, Sawyer JR, Harrison MJ: Radiation-induced meningiomas: clinical, pathological, cytokinetic, and cytogenetic characteristics. J Neurosurg 100:10021013, 2004

5. Albert RE, Omran AR, Brauer EW, Dove DC, Cohen NC, Schmidt H, et al: Follow-up study of patients treated by X-ray for tinea capitis. Am J Public Health Nations Health 56:21142120, 1966

6. Bailey P, Sosman MC, VanDessel A: Roentgen therapy of gliomas of the brain. AJR Rad Ther 19:203-264, 1928

7. Beller AJ, Feinsod M, Sahar A: The possible relationship between small dose irradiation to the scalp and intracranial meningiomas. Neurochirurgia (Stuttg) 15:135-143, 1972

8. Borovich B, Doron Y: Recurrence of intracranial meningiomas: the role played by regional multicentricity. J Neurosurg 64:5863, 1986

9. Borovich B, Doron Y, Braun J, Guilburd JN, Zaaroor M, Goldsher $\mathrm{D}$, et al: Recurrence of intracranial meningiomas: the role played by regional multicentricity. Part 2: Clinical and radiological aspects. J Neurosurg 65:168-171, 1986

10. Brenner DJ, Hall EJ: Computed tomography—an increasing source of radiation exposure. N Engl J Med 357:2277-2284, 2007

11. Caufield C: Multiple Exposures: Chronicles of the Radiation Age. New York: Harper \& Row, 1989

12. Choudhary A, Pradhan S, Huda MF, Mohanty S, Kumar M: Radiation induced meningioma with a short latent period following high dose cranial irradiation-case report and literature review. J Neurooncol 77:73-77, 2006

13. Davidoff L, Dyke CG, Elsberg CA, Tarlov IM: The effect of radiation applied directly to the brain and spinal cord. Radiology 31:451-463, 1938

14. Domenicucci M, Artico M, Nucci F, Salvati M, Ferrante L: Meningioma following high-dose radiation therapy. Case report and review of the literature. Clin Neurol Neurosurg 92:349-352, 1990 
15. Duke University Rare Book, Manuscript, and Special Collections Library: Edison fears the hidden perils of the x-rays. New York Worldb/, Aug 3, 1903. Durham, NC: Rare Book, Manuscript, and Special Collections Library, Duke University (http: //home.gwi. net/ dnb/read/edison/edison_xrays.htm) [Accessed 1 March 2008]

16. Foltz EL, Holyoke JB, Heyl HL: Brain necrosis following X-ray therapy. J Neurosurg 10:423-429, 1953

17. Ghim TT, Seo JJ, O'Brien M, Meacham L, Crocker I, Krawiecki $\mathrm{N}$ : Childhood intracranial meningiomas after high-dose irradiation. Cancer 71:4091-4095, 1993

18. Goldman L, Schwarz J, Preston RH, Beyer A, Loutzenhiser J: Current status of Griseofulvin. JAMA 172:532-538, 1960

19. Goldstein L: Radiogenic microcephaly: a survey of 19 recorded cases, with special reference to ophthalmic defects. Arch Neurol 24:102-115, 1930

20. Gomori JM, Shaked A: Radiation induced meningiomas. Neuroradiology 23:211-212, 1982

21. Goodwin JW, Crowley J, Eyre HJ, Stafford B, Jaeckle KA, Townsend JJ: A phase II evaluation of tamoxifen in unresectable or refractory meningiomas: a Southwest Oncology Group study. J Neurooncol 15:75-77, 1993

22. Gosztonyi G, Slowik F, Pásztor E: Intracranial meningiomas developing at long intervals following low-dose X-ray irradiation of the head. J Neurooncol 70:59-65, 2004

23. Gottfried KD, Penn G: Radiation in Medicine: a Need for Regulatory Reform. Washington, DC: Committee for Review and Evaluation of the Medical Use Program of the Nuclear Regulatory Commission, National Academies of Science, 1996 (http://books.nap.edu/openbook.php?record_id=5154\&page=R1) [Accessed 8 January 2008]

24. Harrison MJ, Wolfe DE, Lau TS, Mitnick RJ, Sachdev VP: Radiation-induced meningiomas: experience at the Mount Sinai Hospital and review of the literature. J Neurosurg 75:564-574, 1991

25. Hendee WR: History, current status, and trends of radiation protection standards. Med Phys 20:1303-1314, 1993

26. Jääskeläinen J: Seemingly complete removal of histologically benign intracranial meningioma: late recurrence rate and factors predicting recurrence in 657 patients. A multivariate analysis. Surg Neurol 26:461-469, 1986

27. Katzenellenbogen I, Sandbank M: [The treatment of tinea capitis and dermatomycosis with griseofulvin. Follow-up of 65 cases.] Harefuah 60:111-115, 1961 (Hebrew)

28. Lee JY, Finkelstein S, Hamilton RL, Rekha R, King JT Jr, Omalu $\mathrm{B}$ : Loss of heterozygosity analysis of benign, atypical, and anaplastic meningiomas. Neurosurgery 55:1163-1173, 2004

29. Longstreth WT Jr, Phillips LE, Drangsholt M, Koepsell TD, Custer BS, Gehrels JA, et al: Dental x-rays and the risk of intracranial meningioma: a population-based case-control study. Cancer 100: 1026-1034, 2004

30. Louis DN, Scheithauer BW, Budka H, von Deimling A, Kepes JJ: Meningiomas, in Kleihues P, Cavenee WK (eds): World Health Organization Classification of Tumours. Pathology and Genetics: Tumors of the Nervous System. Lyon: International Agency for Research on Cancer Press, 2000, pp 176-184

31. Lyman RS, Kupalov PS, Scholz W: Effect of roentgen rays on the central nervous system: results of large doses on brains of adult dogs. Arch Neurol Psychiatry 29:56-87, 1933

32. Mack EE, Wilson CB: Meningiomas induced by high-dose cranial irradiation. J Neurosurg 79:28-31, 1993

33. Mann I, Yates PC, Ainslie JP: Unusual case of double primary orbital tumor. Br J Ophthalmol 37:758-762, 1953

34. Margulis AR: The lessons of radiobiology for diagnostic radiology. Caldwell Lecture, 1972. AJR Radium Ther Nucl Med 117: 741-756, 1973

35. Mason WP, Gentili F, Macdonald DR, Hariharan S, Cruz CR, Abrey LE: Stabilization of disease progression by hydroxyurea in patients with recurrent or unresectable meningioma. J Neurosurg 97:341-346, 2002

36. Mirimanoff RO, Dosoretz DE, Linggood RM, Ojemann RG, Martuza RL: Meningioma: analysis of recurrence and progression following neurosurgical resection. J Neurosurg 62:18-24, 1985

37. Modan B, Baidatz D, Mart H, Steinitz R, Levin SG: Radiationinduced head and neck tumors. Lancet 1:277-279, 1974

38. Morgan RH: The emergence of radiology as a major influence in American medicine. Caldwell Lecture, 1970. AJR Radium Ther Nucl Med 111:449-462, 1971

39. Moss SD, Rockswold GL, Chou SN, Yock D, Berger MS: Radiation-induced meningiomas in pediatric patients. Neurosurgery 22:758-761, 1988

40. Muller HJ: Artificial transmutation of the gene. Science 66:84-87, 1927

41. Munk J, Peyser E, Gruszkiewicz J: Radiation induced intracranial meningiomas. Clin Radiol 20:90-94, 1969

42. Musa BS, Pople IK, Cummins BH: Intracranial meningiomas following irradiation-a growing problem? Br J Neurosurg 9: 629-637, 1995

43. Nader R: Wake up, America: unsafe x-rays. Ladies' Home J 85: 126-127, 1968

44. National Academy of Sciences: Biological Effects of Atomic Radiation: Report to the Public. Washington, DC: National Academy of Sciences, 1956

45. National Academy of Sciences: National Research Council. Committee on the Biological Effects of Ionizing Radiations. The Effects on Populations of Exposure to Low Levels of Ionizing Radiation 1980. Washington, DC: National Academy of Sciences, 1980

46. Nemenow MI: Effect of Roentgen rays on the brain: experimental investigation by means of the conditioned reflex method. Radiology 23:94-96, 1934

47. Newton HB: Hydroxyurea chemotherapy in the treatment of meningiomas. Neurosurg Focus 23:E11, 2007

48. Newton HB, Scott SR, Volpi C: Hydroxyurea chemotherapy for meningiomas: enlarged cohort with extended follow-up. Br J Neurosurg 18:495-499, 2004

49. Newton HB, Slivka MA, Stevens C: Hydroxyurea chemotherapy for unresectable or residual meningioma. J Neurooncol 49: $165-170,2000$

50. Nolan WE: Radiation hazards to the patient from oral roentgenography. J Am Dent Assoc 47:681-684, 1953

51. Nolan WE, Patterson HW: Radiation hazards from the use of dental x-ray units. Radiology 61:625-629, 1953

52. Pollak L, Walach N, Gur R, Schiffer J: Meningiomas after radiotherapy for tinea capitis - still no history. Tumori 84:65-68, 1998

53. Preston DL, Ron E, Yonehara S, Kobuke T, Fujii H, Kishikawa $\mathrm{M}$, et al: Tumors of the nervous system and pituitary gland associated with atomic bomb radiation exposure. J Natl Cancer Inst 94:1555-1563, 2002

54. Preston-Martin S, Paganini-Hill A, Henderson BE, Pike MC, Wood C: Case-control study of intracranial meningiomas in women in Los Angeles County, California. J Natl Cancer Inst 65:67-73, 1980

55. Rabin BM, Meyer JR, Berlin JW, Marymount MH, Palka PS, Russell EJ: Radiation-induced changes in the central nervous system and head and neck. Radiographics 16:1055-1072, 1996

56. Rodvall Y, Ahlbom A, Pershagen G, Nylander M, Spännare B: Dental radiography after age 25 years, amalgam fillings and tumors of the central nervous system. Oral Oncol 34:265-269, 1998

57. Ron E, Modan B, Boice JD Jr, Alfandary E, Stovall M, Chetrit A, et al: Tumors of the brain and nervous system after radiotherapy in childhood. N Engl J Med 319:1033-1039, 1988

58. Rosenthal MA, Ashley DL, Cher L: Treatment of high risk or recurrent meningiomas with hydroxyurea. J Clin Neurosci 9: $156-158,2002$

59. Rubinstein AB, Shalit MN, Cohen ML, Zandbank U, Reichenthal 
E: Radiation-induced cerebral meningioma: a recognizable entity. J Neurosurg 61:966-971, 1984

60. Russell B, Frain-Bell W, Stevenson CJ, Riddell RW, Djavahiszwili N, Morrison SL: Chronic ringworm infection of the skin and nails treated with griseofulvin. Report of a therapeutic trial. Lancet 1:1141-1147, 1960

61. Sachs E, Rubinstein JE, Arneson AN: Results of roentgen treatment of a series of 119 gliomas. Arch Neurol Psychiatry 35: 597-616, 1936

62. Sadamori N, Shibata S, Mine M, Miyazaki H, Miyake H, Kurihara $\mathrm{M}$, et al: Incidence of intracranial meningiomas in Nagasaki atomic-bomb survivors. Int J Cancer 67:318-322, 1996

63. Sadetzki S, Chetrit A, Freedman L, Stovall M, Modan B, Novikov I: Long-term follow-up for brain tumor development after childhood exposure to ionizing radiation for tinea capitis. Radiat Res 163:424-432, 2005

64. Sadetzki S, Flint-Richter P, Ben-Tal T, Nass D: Radiation-induced meningioma: a descriptive study of 253 cases. J Neurosurg 97: 1078-1082, 2002

65. Sadetzki S, Flint-Richter P, Starinsky S, Novikov I, Lerman Y, Goldman B, et al: Genotyping of patients with sporadic and radiation-associated meningiomas. Cancer Epidemiol Biomarkers Prev 14:969-976, 2005

66. Salvati M, Cervoni L, Artico M: High-dose radiation-induced meningiomas following acute lymphoblastic leukemia in children. Childs Nerv Syst 12:266-269, 1996

67. Salvati M, Cervoni L, Puzzilli F, Bristot R, Delfini R, Gagliardi FM: High-dose radiation-induced meningiomas. Surg Neurol 47:435-442, 1997

68. Schrell UM, Rittig MG, Anders M, Koch UH, Marschalek R, Kiesewetter F, et al: Hydroxyurea for treatment of unresectable and recurrent meningiomas. II. Decrease in the size of meningiomas in patients treated with hydroxyurea. J Neurosurg 86: 840-844, 1997

69. Schrell UM, Rittig MG, Koch U, Marschalek R, Anders M: Hydroxyurea for treatment of unresectable meningiomas. Lancet 348:888-889, 1996

70. Shibata S, Sadamori N, Mine M, Sekine I: Intracranial meningiomas among Nagasaki atomic bomb survivors. Lancet 344:1770, 1994
71. Shintani T, Hayakawa N, Hoshi M, Sumida M, Kurisu K, Oki S, et al: High incidence of meningioma among Hiroshima atomic bomb survivors. J Radiat Res 40:49-57, 1999

72. Shintani T, Hayakawa N, Kamada N: High incidence of meningioma in survivors of Hiroshima. Lancet 349:1369, 1997

73. Shoshan Y, Spektor S, Rosenthal G, Fraifeld S, Umansky F: Radiation-induced meningiomas: historical perspective, presentation, management, and genetics, in Lee JH (ed): Meningiomas: Diagnosis, Treatment and Outcome. New York: Springer-Verlag, in press, 2008

74. Simpson D: The recurrence of intracranial meningiomas after surgical treatment. J Neurol Neurosurg Psychiatry 20:22-39, 1957

75. Soffer D, Gomori JM, Siegal T, Shalit MN: Intracranial meningiomas after high-dose irradiation. Cancer 63:1514-1519, 1989

76. Soffer D, Pittaluga S, Feiner M, Beller AJ: Intracranial meningiomas following low-dose irradiation to the head. J Neurosurg 59: 1048-1053, 1983

77. Stechison MT, Burkhart LE: Radiation-induced meningiomas. J Neurosurg 80:177-178, 1994

78. Strojan P, Popovic M, Jereb B: Secondary intracranial meningiomas after high-dose cranial irradiation: report of five cases and review of the literature. Int J Radiat Oncol Biol Phys 48:65-73, 2000

79. Wachowski TJ, Chenault H: Degenerative efffects of large doses of roentgen rays on the human brain. Radiology 45:227-246, 1945

80. Wilson CB: Meningiomas: genetics, malignancy, and the role of radiation in induction and treatment. The Richard C. Schneider Lecture. J Neurosurg 81:666-675, 1994

81. Yousaf I, Byrnes DP, Choudhari KA: Meningiomas induced by high dose cranial irradiation. Br J Neurosurg 17:219-225, 2003

82. Ziprkowski L, Krakowski A, Schewach-Millet M, Btesh S: Griseofulvin in the mass treatment of tinea capitis. Bull World Health Organ 23:803-810, 1960

Manuscript submitted December 20, 2007.

Accepted February 13, 2008.

Address correspondence to: Felix Umansky, M.D., Department of Neurosurgery, Hadassah-Hebrew University Medical Center, POB 12000, Jerusalem, Israel 91110. email: umansky@hadassah. org.il or umansky@ netvision.net.il. 